\title{
Tres historias desde el CEPE sobre el movimiento estudiantil de 1968
}

\author{
Juan Pablo Vivaldo ${ }^{1}$
}

\begin{abstract}
Resumen: Este trabajo representa una aportación desde la historia oral a la reflexión alrededor del movimiento estudiantil de 1968 en la Ciudad de México. Para ello, presento tres entrevistas realizadas al mismo número de trabajadores del Centro de Enseñanza para Extranjeros (CEPE) en las que muestro no solo su contribución al interior del movimiento, sino su percepción sobre él a cincuenta años de distancia. Al mismo tiempo, presento los que considero son los principales antecedentes del conflicto estudiantil en México, así como una serie de reflexiones metodológicas sobre la historia oral.
\end{abstract}

Palabras clave: movimiento estudiantil de 1968, historia oral, CEPE experiencias.

\begin{abstract}
The aim of this paper is to contribute to the reflection around the 1968 student movement in Mexico City from the perspective of Oral History. In order to do so, I present three interviews with the same number of members of the academic and administrative staff of the Center for Foreign Students (CEPE, by its acronym in Spanish). Through the analysis of those interviews, I discuss not only their contributions to the movement, but their current perception of it. At the same time, I present what I consider to be the main antecedents of the student conflict in Mexico, as well as a series of methodological reflections on Oral History.
\end{abstract}

Keywords: 1968 student movement, oral history, CEPE, experiences.

La reflexión sobre el movimiento estudiantil de 1968, no tendría que realizarse solo a partir de una conmemoración o de una coyuntura en particular, sino es necesario traerla una y otra vez al debate para que no caiga en el olvido; debería complementarse con lecturas y aportaciones recientes con el objetivo de que la

\footnotetext{
${ }^{1}$ Doctor en Historia. Profesor de asignatura nivel "B" en el Centro de Enseñanza para Extranjeros (CEPE). Profesor de asignatura nivel "A" en la Facultad de Estudios Superiores Zaragoza (FES Zaragoza), Campus 3, Tlaxcala. Licenciado y maestro en Historia por la Universidad Autónoma Metropolitana y doctor por la Universidad Nacional Autónoma de México. Profesor en el CEPE desde 2012 y en la FES a partir de 2015. Su línea de investigación es la historia de la vejez y del envejecimiento en México.
} 
memoria se renueve constantemente y aparezcan más preguntas con el mayor número de matices; y esto para que las generaciones más recientes de jóvenes universitarios no pierdan de vista que hace medio siglo, hombres y mujeres de todas las edades formaron parte de un movimiento que cambió la percepción sobre los estudiantes en este país.

En este sentido, como ciudadano, historiador y profesor de la Universidad Nacional Autónoma de México, estoy convencido de la necesidad de continuar reflexionando sobre el movimiento estudiantil de 1968. El año pasado se cumplieron 50 años de aquel proceso de la historia de México, resulta pertinente hacer un alto en el camino para volvernos a preguntar sobre sus orígenes y sobre todo para analizar, a la luz de nuevas fuentes, sus alcances y limitaciones.

Como parte del programa de la asignatura Temas selectos de Historia de México que imparto en el Centro de Enseñanza para Extranjeros, dedico una sesión para analizar dicho proceso. De manera gratificante, he observado que los estudiantes extranjeros (que se ubican en un nivel B4) están muy interesados en estudiar el tema, en primer lugar porque no es un tópico que toquen comúnmente en sus clases, y porque su estancia en México coincidió con la conmemoración del 50 aniversario de dicho suceso, lo que los invita a la discusión con sus compañeros mexicanos sobre un periodo clave de este país.

Para preparar dicho curso, empleo una serie de herramientas que persiguen el objetivo de brindar a mis estudiantes distintos enfoques sobre el proceso. De tal suerte, a lo largo de las sesiones revisamos desde los primeros textos sobre el movimiento, como la desgarradora novela Los días y los años de Luis González de Alba, la muy leída y conocida Noche de Tlatelolco de Elena Poniatowska, y México 68: juventud y revolución, análisis de la autoría de José Revueltas sobre el conflicto estudiantil; hasta los más recientes estudios históricos como: Reflexión y crítica en torno al movimiento estudiantil de 1968. Nuevo enfoques y líneas de investigación, y Los primeros días. Una explicación de los orígenes inmediatos del movimiento estudiantil de 1968, de Alberto del Castillo Troncoso y Ariel Rodríguez Kuri, respectivamente. También he empleado otros recursos como propaganda, imágenes y símbolos sobre el movimiento que se encuentran en diversos sitios electrónicos, así como Imágenes y símbolos del 68, trabajo de Arnulfo Aquino, quien fuera dirigente estudiantil de la Escuela de Artes Plásticas en 1968. La música es otro elemento que he incorporado al curso, puesto que:

cada canción como unidad de trabajo representa en sí misma una concepción distinta de la realidad, sujeta a distintas interpretaciones, y transmite una carga cultural y emocional a los alumnos que pueden servirle como verdaderos input que desencadenen un proceso de aprendizaje significativo. (Hornillos\&Villanueva, 2013: 141). 
De esta forma, de la mano de cantautores como Judith Reyes, José de Molina y Óscar Chávez, los estudiantes extranjeros se aproximan al movimiento desde perspectivas distintas, toda vez que cada uno de ellos encuentra en cada canción diferentes matices que complementan su visión del proceso. Pero definitivamente, una fuente que me ha sido de gran utilidad para que comprendan mejor el movimiento estudiantil de 1968, ha sido la historia oral que permite "engranar teóricamente los sucesos que van desde lo local y que repercuten en lo nacional o viceversa" (Lara, 2014:48).

El trabajo que presento tiene que ver con escuchar las experiencias de otros protagonistas que también forman parte de la memoria histórica del movimiento estudiantil, toda vez que la continúan nutriendo con sus reflexiones y compartiéndola con los interesados, convirtiéndose así en una memoria viva y flexible. Estos protagonistas han laborado en el Centro de Enseñanza para Extranjeros (CEPE) durante algunas décadas y han compartido con colegas y estudiantes no solo su conocimiento, sino algunas experiencias que han transformado su vida académica.

Este trabajo se estructura en tres partes. En la primera, me ocupo de brindar un contexto general que le sea útil al lector para ubicarse en el tiempo y en el espacio. En la siguiente sección aparecen una serie de reflexiones metodológicas sobre la historia oral, con las que busco aclarar una serie de elementos que están relacionados con la identificación de mis entrevistados con el movimiento estudiantil, así como con la postura que asume quien funge como entrevistador ante la ideología de quienes narran parte de sus vidas. Finalmente, comparto una narrativa en la que aparecen tres personas que desde hace algunos años ingresaron en el CEPE no solo para fortalecerlo, sino para compartir su experiencia académica y laboral, así como su calidez como seres humanos que contagian con cuantos se cruzan por su camino. Me refiero a las licenciadas Rebeca García, jefa de la biblioteca Simón Bolívar, y María Casillas Hernández, secretaria en nuestro Centro, y al maestro Luis Fernando Rodríguez Lazcano, jefe del Departamento de Arte.

\section{EL CONTEXTO}

Para quienes no vivimos el año de 1968, reflexionar sobre él nos remite a utilizar distintas fuentes históricas: los libros en cuyas páginas tienen impresas a parte de una generación que usó las letras para imaginar otros realidades (en 62 modelo para armar, el escritor argentino Julio Cortázar desapareció la monotonía de los capítulos para permitirle al lector proponer su propio orden para la lectura, mientras que en 2001: una odisea espacial, Arthur C. Clarke, nos regaló una 
novela de ciencia ficción que se encargó de mostrarnos la posibilidad de pensar un posible futuro de la humanidad; la música que invitó a millones de personas a experimentar otros ritmos y letras interpretadas por decenas de jóvenes que se atrevieron a revolucionar a la industria como los integrantes de Led Zepellin, Yes, The Rolling Stones, Black Sabbath y Los Ovnis); o el cine que provocó que en ese año, miles de personas esperaran a que avanzaran largas filas para mirar proyectadas en cines como el "Latino" o "Diana" películas como "2001: una odisea espacial" de Stanley Kubrick, "El bebé de Rosemary" de Roman Polanski, "El amor de María Isabel" y "Por mis pistolas", protagonizadas por Silvia Pinal y Mario Moreno "Cantinflas", respectivamente, así como el siempre terrorífico filme mexicano "Hasta el viento tiene miedo".

Pero para quienes vivieron y experimentaron aquella década, el recuerdo musical se inserta en un contexto socio-cultural que fue testigo del surgimiento de una realidad nacional e internacional mucho más compleja, que dio como consecuencia que se experimentaran una serie de continuidades y cambios de diversa índole que en algunas ocasiones permitieron que las cosas mantuvieran su ritmo inalterable, pero que en otras, sacudieron las formas de pensar y actuar de millones de personas alrededor del mundo y consolidaron revoluciones políticas, sociales y culturales.

De estas últimas destacan los movimientos de liberación nacional contra las políticas coloniales en África (Argelia) y Asia (Indochina y Vietnam), el combate a las dictaduras y el impulso de las guerrillas latinoamericanas a partir del triunfo de la revolución cubana en 1959, así como las protestas que se suscitaron a nivel global en contra de la guerra de Vietnam, y la lucha contra el Apartheid en Sudáfrica bajo el liderazgo de Nelson Mandela. Se trata de elementos que lograron cohesionar fuertes luchas antiimperialistas, cuyos actores principales fueron millones de jóvenes que desde diferentes partes del planeta levantaron la voz para hacerse presentes en una sociedad que generalmente los mantuvo alejados de la toma de decisiones.

De tal suerte, en las siguientes líneas pasaré lista a tres antecedentes internacionales del movimiento estudiantil mexicano de 1968. El primero de ellos fue la intervención estadounidense en Vietnam (1955-1975) auspiciada por el gobierno de Lyndon B. Johnson (1963-1969). Esto detonó una serie de protestas al interior de la misma Unión americana. Una de las más importantes la lideró Martin Luther King (1929-1968), quien fue asesinado en Memphis, Tennesse. Fue en ese contexto en el que un sector de la juventud estadounidense decidió tomar una serie de acciones para demostrar su rechazo a esa política intervencionista, como la del 23 de abril de 1968, cuando estudiantes de la Universidad de Columbia tomaron sus instalaciones con lo que inició una huelga que duraría una semana hasta que fueron desalojados violentamente por la policía. 
El segundo antecedente fue conocido como"la primavera de Praga" que inició de la mano del año de 1968. En el mes de enero tomó forma en Checoslovaquia un movimiento social cuyo objetivo fue "humanizar" al socialismo de inspiración soviética para terminar con el monopolio del partido, lo que se conseguiría al proponer una serie de medidas para la liberalización del régimen político: libertad de expresión, prensa y circulación, así como plantear la discusión sobre la posibilidad de establecer un gobierno multipartidista. Lo anterior desencadenó la movilización de tropas de la Unión de Repúblicas Socialistas Soviéticas (URSS) en territorio checoslovaco, hasta que el 20 de agosto, cerca de medio millón de soldados y más de dos millares de tanques irrumpieron en aquel territorio poniéndole fin al proceso de apertura socialista: la primavera terminó abruptamente.

En tercer lugar, el "mayo francés", un movimiento que nutrió de ideas y de símbolos a la lucha estudiantil y popular a nivel mundial. La historia fue similar: grupos de estudiantes organizados, en particular el llamado "22 de marzo", llamaron a la movilización para denunciar el arresto arbitrario de sus compañeros de la Universidad de Nanterre que protestaron en contra de la guerra de Vietnam, así como del papel que Francia desempeñó en ella.

La represión de la policía no tardó en llegar y se enfrentó con la resistencia organizada de los estudiantes que se manifestaron durante varios días y que lograron que sus ideas revolucionarias se extendieran por la mayor parte de París. Hacia el 10 de mayo, el paisaje urbano se transformó, pues combinó las barricadas en las calles, los cabellos largos y la ropa holgada de los jóvenes franceses, con las homogéneas cabelleras y uniformes de policías que "liberaron" algunas calles parisinas. El movimiento estudiantil se convirtió en social cuando se logró la incorporación del sector obrero a las movilizaciones, de manera tal que el 13 de mayo, y gracias a la participación de nueve millones de trabajadores, Francia quedara paralizada producto de una huelga general. De forma equivalente a la Primavera de Praga, el movimiento estudiantil y obrero en Francia tuvo una corta vida cuando el presidente Charles de Gaulle decretó la disolución de las organizaciones ultraizquierdistas, con lo que varios de sus líderes fueron arrestados.

No puedo dejar de mencionar la represión contra dos movimientos sociales en México: el ferrocarrilero durante 1958 y 1959, y el médico en la capital del país entre 1964 y 1965 (ya con Díaz Ordaz sentado en la silla presidencial). Estos conflictos, en particular el último, mostró la línea que seguiría el abogado poblano para terminar con el movimiento estudiantil de 1968. 
REFLEXIONES METODOLÓGICAS SOBRE LA HISTORIA ORAL

¿Es posible construir conocimiento histórico a partir de la memoria? En la actualidad, la anterior pregunta podría parecer una obviedad puesto que la respuesta es afirmativa. Sin embargo, debemos considerar que la oralidad no siempre fue considerada como una fuente para reconstruir el pasado reciente. La historia tradicional hizo a un lado las biografías y los relatos por considerar que estos se basaban en gran medida en la subjetividad de sus autores.

Sin embargo, en el primer tercio del siglo XX, y ya con fuerza a partir de su segunda mitad, algunos historiadores como los ingleses Edward Palmer Thompson, Eric Hobsbawm, y los franceses Jaques Le Goff y Fernand Braudel, comenzaron a cuestionar las formas tradicionales de acercarse al conocimiento histórico, es decir, se arriesgaron a alejarse de los estudios sobre la política y la economía para acercarse más al análisis de las comunidades y de sus integrantes. Así, las preocupaciones, miedos y angustias, como los motivos que detonaron la felicidad de "los de abajo", fueron considerados como parte de la historia y dignos de ser tomados en cuenta. El estudio de los individuos y su relación con su espacio y su contexto, ya no solo representó un interés tangencial, sino que se convirtió en necesario para una sociedad que se transformaba de forma acelerada.

En México, Alicia Meyer y Alicia Olivera impulsaron la historia oral. Si bien es cierto que el modelo estadounidense tuvo una gran influencia en la década de 1960, en vez de estudiar a las élites, las historiadoras mexicanas se preocuparon por recuperar la historia de otros sectores sociales que no fueron escuchados y que participaron en la construcción de procesos clave de la historia nacional.

En este sentido, la historia oral brinda la posibilidad de que la participación en la construcción de un proceso sea amplia, lo que abre la posibilidad de que cualquier persona sea entrevistada para recrear algún proceso histórico del que haya formado parte. De acuerdo con Graciela de Garay, "tenemos la oportunidad de hacer de la historia oral una metodología de investigación de carácter cualitativo porque busca la subjetividad para rescatar la voz de quienes no se han escuchado, pero también la voz de las élites" (Garay, 2015).

De acuerdo con Mario Camarena y Gerardo Necoechea, existen tres maneras de abordar la historia oral: una consiste en entrevistar con el propósito de complementar otras fuentes; otra en hacerlo para recabar un testimonio el cual es reproducido íntegro, con un trabajo mínimo de edición; por último existen los trabajos de historia oral que hacen de los testimonios su materia de estudio, que idean estrategias de lectura y análisis con el propósito de estudiar el significado de la experiencia de vivir (Camarena \& Necoechea, 1994). 
Las personas entrevistadas accedieron a que hablara de ellos porque consideran que es fundamental que se debata sobre un tema que aún no se comprende del todo, pues aunque el hombre ha avanzado en la comprensión de algunos campos, en el pensamiento social lo ha hecho muy poco, pues como se afirma desde la psicología social "con enorme facilidad nos formamos y mantenemos creencias falsas" (Ovejero, 2007:39).

La entrevista no solo supone un acercamiento al protagonista que vivió "en carne propia" el acontecimiento de interés para el entrevistador, sino una serie de riesgos que Eugenia Meyer y Alicia Olivera han descrito: "la mentira voluntaria, la distorsión de los hechos, o incluso la edad avanzada del sujeto entrevistado cuya memoria puede fallar llevándole por consecuencia a un proceso selectivo, equivocado o deformado de los hechos que relata" por lo que existirá en la mente del entrevistador "la duda de haber llegado realmente a la verdad histórica" (Meyer\&Olivera, 1971: 378).

En este caso en particular, en las entrevistas que realicé para elaborar este artículo, me parece que la aparición de los anteriores elementos fueron mínimos, puesto que las personas expresaron sus opiniones con absoluta libertad y los tres tuvieron en mente el objetivo final de las entrevistas (formar parte primero de un encuentro académico y de una eventual publicación, después). Además, sus percepciones sobre el movimiento estudiantil no fueron homogéneas, en otras palabras, no todas estuvieron a favor o en contra, sino que existió en ellas tanto la crítica como la adopción de una postura definida.

Me parece que es fundamental resaltar lo anterior y relacionarlo con mi práctica al emplear la historia oral como herramienta, puesto que la labor del entrevistador no consiste en la de convertirse en juez de los entrevistados, ni en la del militante comprometido con la defensa de una visión partidaria, más bien, quien pregunta debe ser consciente que su tarea consiste en indagar sobre una historia individual, y que por esa misma razón, quien responde lo hace desde su experiencia repleta de sentimientos y emociones.

De las entrevistas me interesaron principalmente dos elementos: el primero se relaciona con rescatar y compartir las vivencias de María, Rebeca y Luis Fernando con quien ahora da lectura a estas líneas, puesto que es fundamental complementar la memoria del movimiento estudiantil de 1968 desde la perspectiva de otros protagonistas de la historia, y en segundo lugar, con el contraste de sus opiniones sobre el conflicto a medio siglo de su estallido, es decir, me interesa darme cuenta sobre la medida en que se transformó o no su percepción sobre los acontecimientos del verano de 1968. 
TRES VISIONES SOBRE UN MOVIMIENTO

Para entender a los jóvenes que en 1968 se vieron involucrados en el movimiento estudiantil, así como a los adultos que después de cincuenta años continúan reflexionando y preguntándose por su impacto, es necesario reflexionar sobre sus orígenes para entender el contexto en el que se desenvolvieron.

Rebeca García nació en la ciudad de Oaxaca el 15 de febrero de 1952 y permaneció allí hasta los cuatro años de edad, cuando sus padres, oriundos de dicha ciudad, decidieron viajar a la ciudad de México para probar mejor suerte y buscar un mejor futuro a sus tres hijos. Su padre, originalmente tejedor de manteles, encontró trabajo en la capital del país en un estacionamiento lavando autos mientras su madre se dedicaba al hogar. La suerte de la familia comenzó a cambiar cuando el padre consiguió un empleo como conserje en la Secretaría de Educación Pública, por lo que la familia se mudó a vivir al Jardín de niños "Matiana de Aveleyra", en la colonia Portales. En ese momento el panorama escolar de Rebeca cambió, pues se le abrieron las puertas para estudiar la primaria, la secundaria y el bachillerato en la prepa número 6 de la UNAM.

Al concluirla ingresó en la Facultad de Filosofía y Letras donde estudió la licenciatura en Historia. En la segunda parte de la década de 1970 trabajó en la Secretaría de Obras Públicas, en la editorial Porrúa revisando las galeras para los libros, en el Claustro de Sor Juana y finalmente llegó a la biblioteca del CEPE en 1983.

Aunque María Casillas Hernández nació en la ciudad de México, sus padres fueron oriundos de Jalisco: "mi papá era comerciante, se dedicaba a vender materiales para construcción, mi mamá fue ama de casa y siempre estuvo allí". María tuvo 8 hermanos en total y todos ellos contaron con una formación académica (ella estudió Comercio).

Llegóal CEPE en 1965 porque su hermana fue amiga de la señorita Stephenson, quien de acuerdo con María, fue una persona importante de la institución. Así que ocupó la plaza "de un señor que se jubiló, no me acuerdo su nombre porque ni siquiera lo conocí. Y creo que no le vino muy bien la jubilada porque al poco tiempo se murió".

Luis Fernando Rodríguez Lazcano vio la luz en la ciudad de México el 5 de mayo de 1947, "fecha que coincide con el aniversario de la batalla de Puebla y con el centenario de la intervención norteamericana en nuestro país", nos recuerda. Luis Fernando nos comenta que su familia fue de clase media baja, su padre fue comerciante de libros y su madre colaboraba con él. Ambos tuvieron una educación universitaria aunque no se recibieron de sus profesiones (Ciencias Químicas y Odontología, respectivamente). Tuvo cuatro hermanos y todos concluyeron sus estudios universitarios. 
Su infancia lo preparó para una de las actividades fundamentales en su vida: viajar (hasta el momento, ha visitado más de 100 países), puesto que la familia comenzó viviendo en la colonia Narvarte y de ahí la vida lo llevó a la colonia Viaducto Piedad primero, y a Iztacalco y a Tlalpan después. Cursó la educación básica en la escuela "Estado de Chiapas" en la colonia Álamos, en Iztapalapa estudió en la secundaria número 22 , cursó el bachillerato en la preparatoria número 5 y posteriormente la carrera en la Facultad de Arquitectura de donde egresó para después estudiar una maestría en restauración de monumentos. Ingresó al CEPE en enero de 1994.

En este momento vale la pena hacer un alto en el camino y preguntarnos por lo que podemos recuperar de las infancias de nuestros entrevistados. En este sentido, la primera reflexión tiene que ver con el mundo laboral con el que estuvieron en contacto desde pequeños a través de sus padres, pues dichas experiencias sin duda forjaron su carácter y les mostraron un camino a seguir con dignidad y honestidad. Dicho de otro modo, la cultura del esfuerzo y la dedicación estuvieron presentes desde los primeros años de su vida, situación que definitivamente tuvo un gran impacto en ellos. En segundo lugar, la convivencia con sus hermanos seguramente les enseñó a compartir lo que tenían y a solidarizarse con ellos en situaciones complicadas. Finalmente, vale la pena señalar que sus padres carecieron de una cultura política sólida que les permitiera enterarse y cuestionar la realidad nacional, lo que se tradujo en que las charlas con los hijos no estuviera presente dicho elemento.

\section{LA EXPERIENCIA DEL MOVIMIENTO ESTUDIANTIL DE 1968}

Recuerda María que algo que le llamaba particularmente la atención de ese año fue la moda: "la falda corta como en el Rock and Roll, el pelo largo, un poco "hipiosos", pues era la época de "amor y paz". Y sí, mientras en aquella época "la chaviza" se alebrestaba en México bailando a ritmo "a go gó" o entonando "Mugre" del grupo mexicano "Los ovnis", la momiza se consternaba al ver que, a pesar de sus innumerables esfuerzos, sus hijos optaban por el camino de la rebeldía que los llevaba a reunirse con otros chavos en espacios tan disímbolos como la calle, las fiestas, la preparatoria o la universidad.

Fue en la recientemente inaugurada preparatoria número 6 cuando Rebeca tuvo su primer contacto con el movimiento estudiantil. De esa época, ella tiene un gran recuerdo de sus profesores, sobre todo de uno que tenía gran fama entre los estudiantes: Sergio Esquivel, un médico que supo transmitir su entusiasmo a quienes asistían a su curso: "todo mundo iba a su clase, se sentaban en el suelo, nos transmitía seguridad". No obstante, también recuerda que en esa época no 
fue tan fácil para los estudiantes conversar entre ellos y que la crítica hacia la situación del país distaba de ser un ejercicio cotidiano o frecuente.

El movimiento estudiantil le llegó a Rebeca de la mano de la más politizada de sus amigas, Araceli, una joven de clase media que por tener hermanas mayores estudiando en la Facultad de Ciencias, estaba enterada de las demandas de los estudiantes. Fue ella quien la inició en los artificios de la politización estudiantil. Entre risas, Rebeca recuerda que su amiga la invitaba a "botear": "yo ni sabía que era botear, pensé que se refería a aventar un bote". A lo que la amiga le respondió: "Ay Rebeca, vamos a ir con un bote para pedir que nos ayuden para el movimiento, para comprar papel y tinta".

Así que acompañada de su amiga, Rebeca comenzó a enterarse más sobre lo que sucedía a su alrededor, es decir, sobre la represión gubernamental hacia los estudiantes pero también sobre su organización. Asistió a su primera manifestación que se desarrolló al interior del circuito en Ciudad Universitaria. Recuerda que después de algún tiempo de caminar entre los universitarios escuchó que distintas voces comenzaron a gritar: ¡oigan, ahí está el ejército": "Ellos estaban allí, con la bayoneta calada, no recuerdo el día, pero era como la una de la tarde, fue en agosto".

Esa experiencia sin duda fue intensa para una joven que nunca había asistido a una manifestación y que mucho menos se había encontrado con el ejército tan cerca. Fue ahí cuando Rebeca y su amiga decidieron apartarse del lugar: "nos fuimos tranquilitas, no nos pasó nada afortunadamente, fuimos del puente a San Ángel donde está el monumento a Obregón. De ahí nos fuimos a mi casa, llegué tarde, como a las 14:30 y le platiqué a mi mamá (siempre le platicaba lo que hacía), bueno pues se asustó, tenía una persona conocida de ahí, conserje y le dijo que no me dejara salir porque había muchos problemas y que en la prepa ya no daban clases. Entonces mi mamá me dijo: “QQué botear ni qué nada!” y ya no me dejaron salir".

Rebeca subrayó que la invitaron a participar en la manifestación que encabezó el entonces rector de la Universidad, Javier Barros Sierra: “Lástima que yo no estaba politizada porque hubiera ido a esa marcha, me dio miedo, a mi mamá también". Ella comenta que comenzó a tomar conciencia de la represión del gobierno hacia los estudiantes y de la falta de libertad de aquel momento hasta que entró en la facultad, pues aunque tuvo amigos en la prepa muy involucrados, ella tenía en realidad poca información.

Una de sus amigas "totalmente rebelde y politizada" se llamó Margarita Andrade Vallejo. Ella se involucró en la Liga"23 de septiembre" y por ese motivo, fue asesinada. Rebeca la recuerda con cariño: "Fue una mujer que quería lo que hemos querido siempre: justicia, que no hubiera represión, que la pobreza desapareciera... luchaba por cambios en el país. Yo siempre la he admirado, 
aunque a veces todavía le pregunto: Margarita, ¿de qué sirvió que te mataran si las cosas siguen igual o peor en este país?"

Luis Fernando entró en la preparatoria número 5 en 1964. Recuerda que "era bastante ruda" porque la acosaban los grupos de porros. Coincide con Rebeca en el sentido de que la calidad de los profesores era excepcional pues de acuerdo con él: "fue una base muy importante en mi formación profesional: mi vocabulario es extenso gracias a las lecturas que siempre hice pero también a las materias de raíces grecolatinas, en las clases de Biología y Literatura nos obligaban a leer cosas que hasta la fecha sirven. Ahí aprendí a nadar. Hice un poco de esgrima. Tenía unas instalaciones extraordinarias y profesores de primera clase. La base, la estructura, la consolidación de mi educación la veo en la prepa".

Luis Fernando comenta que con sus compañeros se hablaba de muchas cosas:"sobre todo de nuestra situación dentro de la prepa, las charlas bizantinas del fútbol, mujeres, del sexo y de todo ese rollo. Ahí no teníamos una formación muy política, no participas, lo haces después a los dieciocho años cuando tienes que votar y tienes que estar pendiente de la situación".

No fue sino hasta su ingreso en la facultad, en 1967, cuando tomó conciencia de la magnitud del movimiento. Sin embargo, Luis Fernando no se involucró completamente en él puesto que tuvo que trabajar desde muy joven (comenta el arquitecto que iya tiene más de 50 años laborando!). De hecho, durante el primer año de la carrera se tuvo que "dividir" para ayudar a su padre en la librería y después a su madre, quien heredó un taller de fabricación de guantes de piel. De tal suerte, nos comenta que se vio envuelto en el movimiento: "mi participación fue muy relativa, de apoyo más que nada, hacíamos colectas de dinero para hacer mantas y lo que se necesitaba para las manifestaciones".

A partir de su ingreso a la Universidad, Luis Fernando comenzó a empaparse de noticias a través de la televisión, la radio y el periódico. Así se enteró de la represión contra los estudiantes. Eso lo impulsó a involucrarse en el movimiento y asistir a las asambleas de la Facultad de Arquitectura, que de acuerdo con él, "era una de las más participativas". Aunque participó en dos o tres marchas, su situación económica no le permitió apoyar todo el tiempo al movimiento. En ese momento, él no perteneció a ningún comité: "yo participaba, iba a la asamblea, cuando se convocaba una marcha asistía, pero el resto del tiempo tenía que trabajar. Entonces sí era consciente que se tenía que hacer algo, modificar las cosas y pues participaba, pero nada más".

Luis Fernando recuerda que tenía todas las intenciones de asistir al mitin de Tlatelolco "pero por alguna circunstancia del destino no fui. No sé si sea bueno o malo, pero es un sentimiento que traigo vivo todavía". Cuando se enteró de la masacre que el gobierno perpetró contra los estudiantes sintió rabia y 
frustración: "sentimos impotencia porque nosotros lo único que teníamos para demostrar nuestra inconformidad eran los bultos, los gritos, las voces, nuestras pancartas, nunca teníamos piedras, nada de eso. Lo único que teníamos era la fuerza de voluntad, las ganas de diálogo, de que se supiera que estábamos ahí, que se supiera que éramos gente que iba a cambiar el futuro del país.... y en respuesta allí estaban el ejército y la policía con sus armas".

No como estudiante, sino como trabajadora, a María el movimiento la tomó por sorpresa en la entonces Dirección General de Cursos Temporales (el actual CEPE), que era dirigido en ese entonces por María del Carmen Millán. Sus instalaciones fueron unas oficinas dentro de la Facultad de Filosofía y Letras. María recuerda: "ver entrar y salir a los estudiantes de la Facultad de Filosofía. Ahí me di cuenta de todos los movimientos. Estando un día en un concierto muy bonito en el auditorio Justo Sierra entraron los de leyes haciendo su escandalito, empezaron a gritar que saliéramos, que esto que lo otro y así, sucesivamente comenzaron a hacer cosas en la facultad, poniendo letreros, creciendo, creciendo su movimiento".

Debido a que la facultad estaba cerrada y que los estudiantes eran extranjeros, recuerda María que tuvieron que mudarse a unas instalaciones que estaban por terminar en la Escuela de Comercio, cerca del Frontón cerrado: "los estudiantes extranjeros asistieron con cierto temor pero se llevaron las clases con normalidad. Hasta cierto punto porque era incómodo estar en un lugar prestado con unos salones aún no terminados, pero que yo recuerde todo normal porque la instrucción que nos dieron desde la dirección fue que siguiéramos trabajando".

María recuerda tres sucesos: el primero fue cuando dinamitaron la estatua de Miguel Alemán: “De buenas a primeras amaneció sin pecho hasta que ya lo tumbaron". En otra ocasión, experimentó "una corretiza horrible un día que fui a pensiones, allá en la Plaza de la República íbamos mi mamá y yo, me acompañó a cambiar un cheque, yo iba a hacer un viaje y sí nos tocó que venían los estudiantes y la policía, nos tuvimos que esconder, sí fue un poquito impresionante". Finalmente, le viene a la mente cuando algunos de sus compañeros del sindicato la comisionaron para ir a recolectar dinero, así que María recuerda que "con una pena horrible, ahí andaba con mi botecito en la calle". Algo que le quedó grabado en la mente fue la respuesta de algunas personas cuando les pedía colaboración para el movimiento: “¿para que estén de flojos los estudiantes?, ¡ni crea que le voy a dar!". Para María, mucha gente no estaba de acuerdo, pues quienes le respondieron de esa manera fueron hombres y mujeres, jóvenes y adultos.

Desde un principio, María no estuvo de acuerdo con el movimiento pues no le pareció la forma en la que los estudiantes trataron al rector Ignacio Chávez. De hecho, recuerda una ocasión en que "las chicas que no estaban de acuerdo 
quitaron algunas pancartas de las paredes de la escuela, y como sabían mis compañeros que yo no estaba de acuerdo me dijeron: seguro tú fuiste la que los quitaste...sí sí sí....porque a ti no te gusta. A lo que ella respondió: Sí, no me gusta pero yo no les quité sus pancartas".

MiRAdAS A 50 años DE DISTANCIA

A cinco décadas del movimiento estudiantil de 1968, a cincuenta años de distancia, los cambios y las continuidades son notorias en las personas entrevistadas. Es cierto que las circunstancias no son las mismas, también es cierto que en algunos casos se profundiza más o menos en los procesos, pero sin duda el contraste de las ideas es siempre enriquecedor. El ímpetu de la juventud de aquel 1968 es matizado por la vejez del 2018.

Para María Casillas no es labor sencilla hablar sobre el impacto del movimiento estudiantil de 1968: "no sé si sirvió de mucho... se menciona muchísimo el cambio, pero yo no entiendo mucho de eso... no entiendo por qué tanto disgusto... la Universidad les brindó todo lo que querían, no les cobró, tuvieron buenos maestros, no veo la razón por qué dañarla". Pero eso no significa que ella aplauda o comparta la represión hacia los estudiantes: "no entiendo cómo el gobierno pudo ser capaz de actuar así".

Luis Fernando asegura que uno de los elementos positivos que debemos rescatar del movimiento fue el surgimiento de una conciencia estudiantil: "Recuerdo que la UNAM y el Poli[técnico] éramos como enemigos tradicionales, más que nada por el futbol americano, pero esa enemistad se terminó en el 68 cuando adquirimos la conciencia de que formamos parte de una ciudad, de un país, de un pueblo, de que somos todos y que si ellos eran reprimidos, nosotros también podíamos serlo".

Luis Fernando sostiene que quienes participaron en el movimiento fueron actores sociales que promovieron un cambio, aunque en la actualidad la situación de país esté peor que antes. En ese sentido reflexiona: ¿Qué padre deja a sus hijos salir actualmente? Yo cuando era joven podía ir a acampar a cualquier lugar. ¿Quién va y acampa ahora? ¿Dónde puedes ir? ¿En lugares cerrados? Eso no es campismo, es otra cosa. $Y$ es que el problema es que te pueden agarrar o confundir, ahí tenemos Canoa, donde la comunidad confundió y asesinó a los estudiantes. La población vive en una completa inseguridad dominada por una serie de grupos que no tienen cara, los periodistas se están muriendo por informar". Derivado de todo esto Luis Fernando reflexiona después de cincuenta años: "ahora me pregunto dónde quedó ese movimiento, dónde están esos gritos que salimos a pegar". 
Para Rebeca, el movimiento significó "una apertura hacia un conocimiento mejor de nosotros como pueblo que necesitaba cambiar porque tratábamos de ser diferentes". Respecto de la conmemoración de los cincuenta años refiere que: "es importante que se recuerde cómo se inició, las personas que murieron o han muerto por ideales que no se han logrado. Es muy importante que la gente sepa cómo la UNAM y el Poli lucharon porque este país cambiara, que los estudiantes sepan, que se les diga, que se les hable [sobre el tema]".

\section{CONCLUSIONES}

¿Qué podemos rescatar de estas líneas? Yo planteo dos ideas: en primer lugar, que la historia oral es una herramienta de gran utilidad para recuperar otras visiones que enriquezcan los procesos, pero también para entender la naturaleza de otros seres humanos tan valiosos como nosotros. Es fundamental comprender que su uso en nuestras clases con los estudiantes extranjeros es enriquecedor, toda vez que las personas entrevistadas suelen hablar de su contexto, de su visión, de su mundo y por ende, el estudiante adquiere más repertorios sobre nuestro país y su cultura.

En segundo lugar, debemos entender que las personas no se explican sin su contexto. Comenté anteriormente que las experiencias durante las infancias de los entrevistados fueron definitorias en sus vidas, toda vez que vieron en sus padres ejemplos claros de trabajo honesto y de preocupación por el bienestar de la familia. Pero también es fundamental darse cuenta que involucrarse en un movimiento va más allá del simple hecho de estar ubicado en un mismo espacio geográfico, es decir, para formar parte de una transformación debemos tener la sensibilidad suficiente para identificarnos en el otro, así como entender que se debe buscar el beneficio colectivo y no solo el individual. 
BiBLIOGRAFÍA

Aquino, A. \& Perezvega, J. (2008). Imágenes y símbolos del 68. México: Universidad Nacional Autónoma de México.

Camarena, M., Necoechea, G (1994). Conversación única e irrepetible: lo singular de la historia oral (47-61). En Graciela de Garay [coord.] La historia con micrófono. Textos introductorios a la historia oral. México: Instituto Mora.

CAstillo, Alberto del (2012). Reflexión y crítica en torno al movimiento estudiantil de 1968. Nuevos enfoques y líneas de investigación. México: Instituto Mora.

GARAY, G. (2015). Un acercamiento a la historia oral. Recuperado de: https://www. youtube.com/watch?v=Z7FtKVBncuE

GonzÁlez, L. (2018). Los días y los años. México: Ediciones cal y arena.

HoRnillos, R.C. \& Villanueva, J. (2015). La música, un instrumento en la enseñanza del español como lengua extranjera mediante la aplicación de las nuevas tecnologías. Porta Linguarum, 23, 139-151.

LARA, P. (2014). La historia oral como alternativa metodológica para las ciencias sociales. Revista de teoría y didáctica de las ciencias sociales, 20, 45-62.

Ovejero, A. (2007). Las relaciones humanas. Psicología social teórica aplicada. Madrid: Biblioteca Nueva.

PoniatowsKa, E. (2017). La noche de Tlatelolco. México: ERA.

Revueltas, J. (2016). México 68. Juventud y revolución. México: ERA.

Rodríguez, A. (2003). Los primeros días. Una explicación de los orígenes inmediatos del movimiento estudiantil de 1968. Historia Mexicana, 53 (1), 179-228. 
